\title{
Attributive subcomparatives in Japanese
}

\author{
Akane Ohtaka*
}

\begin{abstract}
This paper aims to explain the difference in grammaticality between Japanese attributive subcomparatives with quantity adjectives (e.g., ooku/takusan 'many') and those with non-quantity adjectives (e.g., omosiroi 'interesting'). My analysis assumes that Japanese clausal comparatives involve degree abstraction (Shimoyama 2012, see also Bhatt and Takahashi 2011). Degree abstraction is generally assumed to require movement of a null degree operator. In the case of attributive clausal comparatives, the movement takes place from the left branch position. If no operation that alleviates a left branch island violation is available, we would expect that the resulting sentences would be ungrammatical. I propose that in Japanese, quantifier float can play a role in ameliorating extraction out of the left branch islands. More specifically, I argue that (i) Japanese attributive subcomparatives with quantity adjectives involve quantifier float of the quantity adjectives, and that (ii) quantifier float carries the degree operators associated with the adjectives to a position where degree operator movement can originate.
\end{abstract}

Keywords. comparatives; attributive subcomparatives; quantifier float; left branch condition; Japanese

1. Introduction. Comparatives have constituted one of the core areas of linguistic research. Previous literature on comparatives has highlighted cross-linguistic variation in the syntax and semantics of comparison. For example, much discussion has centered on whether Japanese clausal comparatives differ from their English counterparts with respect to the availability of degree abstraction (e.g., Beck et al. 2004, Shimoyama 2012, Sudo 2015). This paper focuses on Japanese attributive subcomparatives, and assuming (following Shimoyama 2012) Japanese clausal comparatives involve degree abstraction, I propose an analysis of how degree abstraction is possible in Japanese attributive subcomparatives.

Kennedy and Merchant (2000) observe that attributive subcomparatives are different from attributive comparatives in two aspects. First, although they both contain a phrase that is not phonologically realized, in the former, the phonologically null phrase is as large as an AP, while in the latter, it is as large as a DP. Second, they differ in that the former is possible only with quantity adjectives (e.g., many), while the latter is possible with both quantity adjectives and non-quantity adjectives (e.g., interesting). These points are illustrated with English examples in (1)-(4).

(1) Subcomparative - quantity adjective (Kennedy and Merchant 2000: (4)) Michael Jordan has more scoring titles than Dennis Rodman has $\Delta$ tattoos.

(2) Subcomparative - non-quantity adjective (Kennedy and Merchant 2000: (7))

* Pico wrote a more interesting novel than Brio wrote a $\Delta$ play.

Comparative - quantity adjective ${ }^{1}$

Michael Jordan has more scoring titles than Dennis Rodman has $\Delta$.

\footnotetext{
* I thank Peter Alrenga and Shoichi Takahashi for valuable comments and discussion. All errors are, of course, my own. Author: Akane Ohtaka, Rutgers University (akane.ohtaka@rutgers.edu).

1 This example is based on data from Kennedy (2002: (16)).
} 
(4) Comparative - non-quantity adjective (Kennedy and Merchant 2000: (10))

Pico wrote a more interesting novel than Brio wrote $\Delta$.

The restriction on the adjectives used can also be observed in Japanese attributive subcomparatives (Shimoyama 2012, Sudo 2015); they are possible only with quantity adjectives:

(5) Quantity adjective (Shimoyama 2012: (61))

Taro-wa [Hanako-ga hon-o katta]-yori ooku-no zassi-o katta.

Taro-TOP Hanako-NOM book-ACC bought-than many-GEN magazine-ACC bought

'Taro bought more magazines than Hanako bought books.'

(6) Non-quantity adjective (Shimoyama 2012: (62))

* Taro-wa [Hanako-ga syoosetu-o kaita]-yori omosiroi ronbun-o kaita.

Taro-TOP Hanako-NOM novel-ACC wrote-than interesting paper-ACC wrote

(Lit.) 'Taro wrote a more interesting paper than Hanako wrote a novel.'

The contrast between (5) and (6) suggests that in attributive subcomparatives with quantity adjectives, some property specific to quantity adjectives plays a role in rescuing otherwise ungrammatical sentences.

In what follows, I argue that in Japanese attributive subcomparatives with quantity adjectives, the adjectives can float. When they float, they "smuggle" the degree operators associated with them to a position from which the operators can undergo degree operator movement.

This paper is organized as follows: in Section 2, I first elaborate on the assumption that clausal comparatives involve degree operator movement. The discussion highlights the need for operations that alleviate left branch effects. I then present an analysis of Japanese attributive subcomparatives. I propose that in Japanese attributive subcomparatives, quantifier float can ameliorate extraction out of the left branch islands. In Section 3, I turn to the two assumptions that the analysis in this paper makes: (i) Japanese attributive subcomparatives with quantity adjectives involve quantifier float of the quantity adjectives, and (ii) quantifier float carries the degree operators associated with the adjectives to a position where degree operator movement can originate. I present evidence for each of these assumptions. In Section 4, I provide a conclusion.

2. Quantifier float analysis. We saw above that in Japanese, like in English, attributive subcomparatives are possible only with quantity adjectives (Shimoyama 2012, Sudo 2015). In this section, I propose that this is because only quantity adjectives can escape the left branch islands created by their host nouns.

More specifically, following Shimoyama, I first assume that Japanese clausal comparatives involve degree abstraction (see also Bhatt and Takahashi 2011). Degree abstraction is generally assumed to require movement of a null degree operator. In the case of attributive clausal comparatives, the movement takes place from the left branch position. Hence, if no operation that alleviates a left branch island violation is available, we would expect that the resulting sentences would be ungrammatical. I propose that in Japanese, quantifier float can play a role in ameliorating extraction out of the left branch islands. Crucially, we see that only quantity adjectives can float.

In what follows, I first elaborate on the assumption that clausal comparatives involve degree operator movement in Section 2.1. The discussion highlights the need for operations that alleviate left branch effects. I then present the analysis in Section 2.2. 
2.1. LEFT BRANCH CONDition. As mentioned above, Shimoyama (2012) analyzes Japanese clausal comparatives as involving degree abstraction. One argument for this analysis is the contrast in possible readings between (7) and (8); while the former has a de dicto reading, the latter does not (Shimoyama 2012: (24)-(26)).

(7) Clausal complement (Shimoyama 2012: (24))

Taro-wa [Hanako-ga hosigatteita]-yori takusan-no onigiri-o katta.

Taro-TOP Hanako-NOM wanted-than many-GEN rice.ball-ACC bought

'Taro bought more rice balls than Hanako wanted.'

$\rightarrow$ can be used in the context where Hanako wanted (to buy) three rice balls, but not any specific ones, and Taro bought five rice balls. (de dicto)

-No DP complement (Shimoyama 2012: (26))

Taro-wa [[Hanako-ga hosigatteita]-no]-yori takusan-no onigiri-o katta.

Taro-TOP Hanako-NOM wanted-NO-than many-GEN rice.ball-ACC bought

'Taro bought more rice balls than \{what/the ones\} Hanako wanted.'

$\rightarrow$ cannot be used in the context above. (no de dicto)

This contrast can be explained if we assume that only (7) involves degree abstraction. That is, in the complement of -yori 'than' in (7), the degree operator associated with many takes narrow scope with respect to the intensional verb want, which gives rise to a de dicto reading. The analysis of (7) is given in (9). ${ }^{2}$

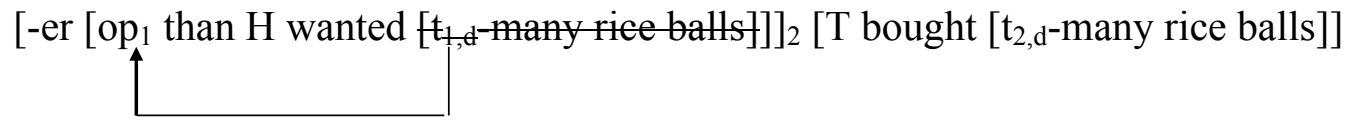

In (8), the complement of -yori is headed by the noun-forming morpheme -no; it is a nominal complement, despite its clausal appearance. The complement involves maximalization over individuals rather than maximalization over degrees. Hence, scope interaction such as the one we saw in (9) does not take place in (8) (Shimoyama 2012: 90-92).

Shimoyama provides further evidence for the degree analysis of Japanese clausal comparatives. Based on her observations, I assume that Japanese clausal comparatives involve movement of a null degree operator. ${ }^{3}$

In the case of attributive clausal comparatives, the movement takes place from the prenominal position, as illustrated in (10). Note that a similar type of movement is ruled out in (11) by the left branch condition. The contrast between these two cases raises the question of why cases such as (10) are not excluded by the left branch condition.

(10) No left branch effect (Lechner and Corver 2017: (102) with a slight modification)

a. John met more linguists than Bill met.

b. John met more linguists [op 1 than Bill met [t $t_{1, \mathrm{~d}}$-many linguists]].

(11) Left branch effect (Lechner and Corver 2017: (99) with a slight modification)

a. * How many did you meet linguists?

b. * [How many $]_{1}$ did you meet $\left[\mathrm{t}_{1}\right.$ linguists $]$ ?

Kennedy and Merchant (2000) argue that in the case of attributive clausal comparatives such as (12b), the complement of than involves deletion of the DP containing the base position of the

\footnotetext{
2 This structure is based on the one in Shimoyama (2012: (25)).

${ }^{3}$ See Beck et al. (2004) and Sudo (2015) for alternative analyses.
} 
movement, and that deletion ameliorates a left branch island violation. ${ }^{4}$ This explains why attributive subcomparatives such as (12d) are not possible, while attributive comparatives such as (12b) are possible. In the former, deletion does not target the DP layer, but just the lower AP layer (e.g., (12e)). Hence, the left branch island will be left pronounced, leading to ungrammaticality. 5

(12) a. Left branch effect - non-quantity adjective (Kennedy and Merchant 2000: (9))

* How interesting did Pico write a novel?

b. Comparative - non-quantity adjective (Kennedy and Merchant 2000: (10))

Pico wrote a more interesting novel than Brio wrote.

c. Pico wrote a more interesting novel [op 1 than Brio wrote [an $t_{1, d}$-interesting novel]].

d. Subcomparative - non-quantity adjective (Kennedy and Merchant 2000: (7))

* Pico wrote a more interesting novel than Brio wrote a play.

e. * Pico wrote a more interesting novel [op $p_{1}$ than Brio wrote [an $\mathfrak{t}_{1, \mathrm{~d}}$-interesting play]].

In the cases in (12), the non-quantity adjective interesting is used. A puzzle arises when we look at cases with quantity adjectives. Let us first consider the comparative sentence in (13b), where the quantity adjective many is used. In (13b), as in (12b), deletion of the DP improves extraction out of the left branch. The analysis of (13b) is given in (13c).

(13) a. Left branch effect - quantity adjective (Kennedy and Merchant 2000: (6))

* How many does Dennis Rodman have tattoos?

b. Comparative - quantity adjective ${ }^{6}$

Michael Jordan has more scoring titles than Dennis Rodman has.

c. Michael Jordan has more scoring titles [op ${ }_{1}$ than Dennis Rodman has $\left[t_{1, \mathrm{~d}}\right.$-many scoring titles]].

Based on this parallelism between non-quantity adjectives and quantity adjectives in attributive comparatives, we would expect that attributive subcomparatives with quantity adjectives would be ungrammatical, like those with non-quantity adjectives (e.g., (12d)). However, this is not the case, as shown in (14a).

(14) a. Subcomparative - quantity adjective (Kennedy and Merchant 2000: (4)) Michael Jordan has more scoring titles than Dennis Rodman has tattoos.

b. Michael Jordan has more scoring titles [op 1 than Dennis Rodman has $\left[\mathrm{t}_{1, \mathrm{~d}}\right.$-many tattoos]].

${ }^{4}$ Kennedy and Merchant (2000) and Fox and Lasnik (2003) show that deletion of the VP also exhibits an island repair property in attributive clausal comparatives (e.g., (i)). See also Merchant (2008) for further discussion.

(i) Island amelioration effect (Fox and Lasnik 2003: (10) with some modifications)

Pico wrote a more interesting novel [op ${ }_{1}$ than Brio did [write an $t_{1, d}$-interesting novel]].

Note that here and elsewhere in this paper, I follow Shimoyama (2012) and Lechner and Corver (2017) in assuming that, in clausal comparatives, only a null degree operator associated with the attributive adjective moves out of the left branch island. Kennedy and Merchant assume that not just a null degree operator, but rather a null degree phrase (e.g., a null counterpart of how interesting), is extracted from the left branch island. In this respect, Fox and Lasnik seem to follow Kennedy and Merchant. See Fox and Lasnik (2003: (10)) for their analysis of (i).

${ }^{5}$ The discussion in the rest of this section (Section 2.1) is based on Kennedy and Merchant (2000).

${ }^{6}$ See fn. 1. 
The contrast between (12d) and (14a) (repeated below in (15) and (16)) leads us to assume that, in attributive subcomparatives with quantity adjectives, some property specific to quantity adjectives plays a role in ameliorating left branch effects.

(15) Subcomparative - non-quantity adjective (Kennedy and Merchant 2000: (7))

* Pico wrote a more interesting novel than Brio wrote a play.

(16) Subcomparative - quantity adjective (Kennedy and Merchant 2000: (4))

Michael Jordan has more scoring titles than Dennis Rodman has tattoos.

The same contrast as the one between (15) and (16) is observed in attributive subcomparatives in Japanese (Shimoyama 2012, Sudo 2015). In the next section, I propose that in the case of Japanese attributive subcomparatives, quantifier float can ameliorate extraction out of the left branch islands. ${ }^{7}$ I shed light on the fact that only quantity adjectives can float.

2.2. QUANTIFIER FLOAT ANALYSIS. We saw above that in English, attributive subcomparatives are possible only with quantity adjectives. The same is true in Japanese, as shown by the contrast between (17) and (18).

(17) Subcomparative - non-quantity adjective (Shimoyama 2012: (62))

* Taro-wa [Hanako-ga syoosetu-o kaita]-yori omosiroi ronbun-o kaita.

Taro-TOP Hanako-NOM novel-ACC wrote-than interesting paper-ACC wrote (Lit.) 'Taro wrote a more interesting paper than Hanako wrote a novel.'

(18) Subcomparative - quantity adjective (Shimoyama 2012: (61))

Taro-wa [Hanako-ga hon-o katta]-yori ooku-no zassi-o katta.

Taro-TOP Hanako-NOM book-ACC bought-than many-GEN magazine-ACC bought

'Taro bought more magazines than Hanako bought books.'

This contrast is unexpected under the assumption that attributive subcomparatives with quantity adjectives, like those with non-quantity adjectives, only involve deletion that targets the AP layer. Something else must be responsible for the contrast between (17) and (18).

Note that non-quantity adjectives and quantity adjectives are different in that the latter can appear in post-nominal position, but not the former. This is illustrated by the contrast between (19b) and (20b). I propose that this property of quantity adjectives plays an important role in rescuing otherwise ungrammatical sentences.

(19) No quantifier float - non-quantity adjective

a. Hanako-ga [omosiroi syoosetu]-o kaita.

Hanako-NOM interesting novel-ACC wrote

'Hanako wrote an interesting novel.'

b. * Hanako-ga syoosetu-o omosiroi kaita. Hanako-NOM novel-ACC interesting wrote

(20) Quantifier float - quantity adjective

a. Hanako-ga [\{ooku/takusan\}-no hon]-o katta.

Hanako-NOM many-GEN book-ACC bought

'Hanako bought many books.'

b. Hanako-ga hon-o \{ooku/takusan $\}$ katta.

Hanako-NOM book-ACC many-GEN bought

\footnotetext{
${ }^{7}$ See Kennedy and Merchant (2000) and Kennedy (2002), among others, for analyses of English attributive subcomparatives.
} 
More specifically, I propose that the derivation of yori-clauses in attributive subcomparatives such as (18) (repeated below in (21)), where the quantity adjective many is used, proceeds as follows: first, a noun combines with a quantity adjective, forming a noun phrase. At this point, the adjective occupies the left branch position of the noun phrase (e.g., (22a)). I assume that this position is defined in relation to the position of the noun. Once the noun has moved stranding the adjective, the adjective is no longer in the left branch position (e.g., (22b)). Following Fitzpatrick (2006), I call the process of adjective stranding "quantifier float". After quantifier float takes place, the degree operator associated with the adjective moves (e.g., (22c)). This makes degree abstraction possible (e.g., (23)).

(21) Subcomparative - quantity adjective (Shimoyama 2012: (61))

Taro-wa [Hanako-ga hon-o katta]-yori ooku-no zassi-o katta. Taro-TOP Hanako-NOM book-ACC bought-than many-GEN magazine-ACC bought 'Taro bought more magazines than Hanako bought books.'

(22) a. [op 1 -many books $] \rightarrow$ quantifier float $\rightarrow$

b. $\quad[$ books $]$ op $_{1}-$ many $] \rightarrow$ degree operator movement $\rightarrow$

c. [op ${ }_{1}$ than Hanako bought [[books $] \mathrm{t}_{1} \mathrm{~d}$-many $\left.]\right]$

(23) $\left[-e r\left[p_{1} \text { than Hanako bought }\left[[\text { books }] \mathfrak{t}_{1, \mathrm{~d}} \text {-many }\right]\right]\right]_{2}$ [Taro bought [magazines $\mathrm{t}_{2, \mathrm{~d}}$-many]]

Let us turn to the derivation of yori-clauses in attributive subcomparatives such as (17) (repeated below in (24)), where the non-quantity adjective interesting is used. The first step is the same as before, except for the type of adjective used; this time, a noun combines with a nonquantity adjective to form a noun phrase (e.g., (25)). We saw above that non-quantity adjectives, unlike quantity adjectives, cannot float. This means that the non-quantity adjective combined with the noun will be trapped inside the left branch position throughout the derivation. This makes degree abstraction impossible. Hence, attributive subcomparatives are impossible with non-quantity adjectives (e.g., (26)).

(24) Subcomparative - non-quantity adjective (Shimoyama 2012: (62))

* Taro-wa [Hanako-ga syoosetu-o kaita]-yori omosiroi ronbun-o kaita.

Taro-TOP Hanako-NOM novel-ACC wrote-than interesting paper-ACC wrote (Lit.) 'Taro wrote a more interesting paper than Hanako wrote a novel.'

(25) [a o p $_{1}$-interesting novel $] \rightarrow$ no quantifier float

$(26) *$ [-er [than Hanako wrote [a op ${ }_{1}$-interesting novel]] $]_{2}$ [Taro wrote [a $t_{2, d}$-interesting paper]

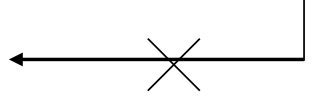

In this section, I have proposed that in Japanese, attributive subcomparatives with quantity adjectives involve quantifier float and degree operator movement. As we have seen, quantifier float plays a role in improving extraction of degree operators out of the host noun phrases. In the rest of this paper, I show that attributive subcomparatives with quantity adjectives in Japanese do involve quantifier float and degree abstraction.

3. Evidence. The current analysis of Japanese attributive subcomparatives with quantity adjectives has two components. First, I assume that they involve quantifier float of the quantity adjectives. Second, I assume that quantifier float carries the degree operators associated with the 
adjectives to a position where degree operator movement can originate; hence, degree operator movement is possible. In this section, I present evidence for each of these assumptions.

First, I focus on the first assumption. If the first assumption is correct, we should expect that when quantifier float is blocked, the sentences would become ungrammatical. Nakanishi (2004) and Fitzpatrick (2006), among others, argue that quantifier float is incompatible with individuallevel predicates. In Section 3.1, I show that when the main predicate in the yori-clause is an individual-level predicate, attributive subcomparatives become impossible.

Next, in Section 3.2, I turn to the second assumption. We saw above that when a sentence involves degree operator movement, it can have a de dicto reading (Shimoyama 2012). If attributive subcomparatives involve degree operator movement, we should expect that they could have a de dicto reading. We see that this is indeed the case.

3.1. EVIDENCE FOR QUANTIFIER FlOAT. According to Nakanishi (2004) and Fitzpatrick (2006), among others, quantifier float is constrained by the type of main predicate of a sentence. For example, when the main predicate is a stage-level predicate, as in (27a), quantifier float is possible, as illustrated in (27b). When the main predicate is an individual-level predicate, as in (28a), quantifier float is impossible, as illustrated in (28b).

(27) Stage-level predicate (Fitzpatrick 2006: 130, (88) with some modifications)

a. [San-too-no kaba]-ga okotteiru.

three-CL-GEN hippo-NOM be.angry

'Three hippos are angry.'

b. Kaba-ga san-too okotteiru. hippo-NOM three-CL be.angry

(28) Individual-level predicate (Fitzpatrick 2006: 130, (88) with some modifications)

a. [San-too-no kaba]-ga kasikoi.

three-CL-GEN hippo-NOM smart

'Three hippos are smart.'

b. * Kaba-ga san-too kasikoi. hippo-NOM three-CL smart

If Japanese attributive subcomparatives with quantity adjectives involve quantifier float, we would predict that they would be possible only with stage-level predicates; those with individuallevel predicates should become ungrammatical, since, as we just saw, individual-level predicates disallow quantifier float. As a result, the quantity adjectives fail to carry the degree operators out of the left branch islands.

This prediction is borne out. As we can see in (29) and (30), the case with a stage-level predicate is grammatical, while that with an individual-level predicate is not.

(29) Subcomparative - stage-level predicate

[Kaba-ga okotteiru]-yori [takusan-no usagi]-ga okotteiru.

hippo-NOM be.angry-than many-GEN rabbit-NOM be.angry

(Lit.) 'More rabbits are angry than hippos are angry.'

(= More rabbits than hippos are angry.)

(30) Subcomparative - individual-level predicate

??[Kaba-ga kasikoi]-yori [takusan-no usagi]-ga kasikoi.

hippo-NOM smart-than many-GEN rabbit-NOM smart

(Lit.) 'More rabbits are smart than hippos are smart.'

(= More rabbits than hippos are smart.) 
This is because in the yori-clause in (29), quantifier float takes place, and this feeds degree operator movement, as illustrated in (31).

$\left[\text {-er }\left[\text { op }_{1} \text { than }\left[[\text { hippos }] \mathrm{t}_{1, \mathrm{~d}} \text {-many }\right] \text { are angry }\right]\right]_{2}\left[\left[\right.\right.$ rabbits $t_{2, \mathrm{~d}}$-many $]$ are angry $]$

Degree operator movement is impossible in (30) because the main predicate in the yoriclause is incompatible with quantifier float. Accordingly, the degree operator is trapped inside the left branch island. This is illustrated in (32).

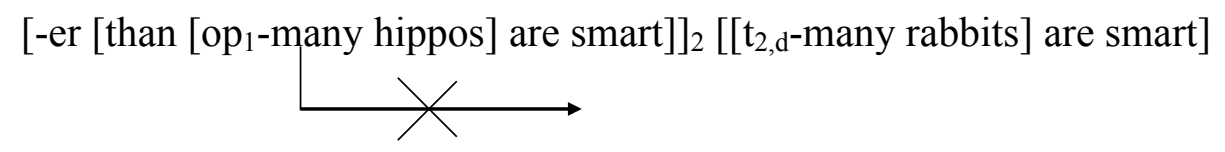

3.2. EVIDENCE FOR DEGREE OPERATOR MOVEMENT. Having established that Japanese attributive subcomparatives involve quantifier float, let us now address the question of whether they also involve degree operator movement. In Section 2.1, we saw that one argument for the degree analysis of clausal comparatives is the contrast in possible readings between (33) and (34); while the former has a de dicto reading, the latter does not (Shimoyama 2012: (24)-(26)).

(33) Clausal complement (Shimoyama 2012: (24))

Taro-wa [Hanako-ga hosigatteita]-yori takusan-no onigiri-o katta.

Taro-TOP Hanako-NOM wanted-than many-GEN rice.ball-ACC bought

'Taro bought more rice balls than Hanako wanted.'

$\rightarrow$ can be used in the context where Hanako wanted (to buy) three rice balls, but not any specific ones, and Taro bought five rice balls. (de dicto)

(34)

-No DP complement (Shimoyama 2012: (26))

Taro-wa [[Hanako-ga hosigatteita]-no]-yori takusan-no onigiri-o katta.

Taro-TOP Hanako-NOM wanted-NO-than many-GEN rice.ball-ACC bought

'Taro bought more rice balls than \{what/the ones\} Hanako wanted.'

$\rightarrow$ cannot be used in the context above. (no de dicto)

As we already saw, this contrast arises because the yori-complement in (33) involves maximalization over degrees, while that in (34) involves maximalization over individuals. That is, only in the yori-complement in (33), the degree operator associated with many can scopally interact with the intensional verb want, which gives rise to a de dicto reading (Shimoyama 2012: 90-92).

Now let us turn to (35), which is an instance of attributive subcomparatives with quantity adjectives. If (35) involves degree abstraction, then it should be able to have a de dicto reading, patterning with (33). This prediction is borne out; (35) can be used in the context where Hanako wanted (to buy) three doughnuts, but not any specific ones, and Taro bought five rice balls.

(35) Subcomparative

Taro-wa [Hanako-ga doughnuts-o hosigatteita]-yori takusan-no onigiri-o

Taro-TOP Hanako-NOM doughnuts-ACC wanted-than many-GEN rice.ball-ACC

katta.

bought

'Taro bought more rice balls than Hanako wanted doughnuts.'

$\rightarrow$ can be used in the context where Hanako wanted (to buy) three doughnuts, but not any specific ones, and Taro bought five rice balls. (de dicto) 
The analysis of (35) is given in (36). In (36), the degree operator associated with many in the yori-clause can scopally interact with the intensional verb want.

$\left[\text {-er }\left[\mathrm{op}_{1} \text { than } \mathrm{H} \text { wanted }\left[[\text { doughnuts }] \mathrm{t}_{\mathrm{p}_{\mathrm{d}}} \text {-many }\right]\right]\right]_{2}\left[\mathrm{~T}\right.$ bought $\left[\right.$ rice balls $\mathrm{t}_{2, \mathrm{~d}}$-many $\left.]\right]$

When the complement of yori in (35) is combined with the noun-forming morpheme -no, as in (37), the de dicto reading becomes unavailable; (37) cannot be used in the context where Hanako wanted (to buy) three doughnuts, but not any specific ones, and Taro bought five rice balls.

(37) -No DP complement

Taro-wa [[Hanako-ga doughnuts-o hosigatteita]-no]-yori takusan-no

Taro-TOP Hanako-NOM doughnuts-ACC wanted-NO-than many-GEN

onigiri-o katta.

rice.ball-ACC bought

'Taro bought more rice balls than the doughnuts Hanako wanted.'

$\rightarrow$ cannot be used in the context above. (no de dicto)

4. Conclusion. In this paper, assuming (following Shimoyama 2012) Japanese clausal comparatives involve degree abstraction, I have proposed an analysis of how degree abstraction is possible in Japanese attributive subcomparatives.

We have seen that attributive subcomparatives are possible only with quantity adjectives, while attributive comparatives are possible with both quantity adjectives and non-quantity adjectives (e.g., Kennedy and Merchant 2000). The restriction on the adjectives used is illustrated in (38) and (39):

(38) Quantity adjective (Shimoyama 2012: (61))

Taro-wa [Hanako-ga hon-o katta]-yori ooku-no zassi-o katta.

Taro-TOP Hanako-NOM book-ACC bought-than many-GEN magazine-ACC bought 'Taro bought more magazines than Hanako bought books.'

(39) Non-quantity adjective (Shimoyama 2012: (62))

* Taro-wa [Hanako-ga syoosetu-o kaita]-yori omosiroi ronbun-o kaita.

Taro-TOP Hanako-NOM novel-ACC wrote-than interesting paper-ACC wrote (Lit.) 'Taro wrote a more interesting paper than Hanako wrote a novel.'

This contrast suggests that in attributive subcomparatives with quantity adjectives, some property specific to quantity adjectives plays a role in rescuing otherwise ungrammatical sentences.

I have argued that in Japanese attributive subcomparatives with quantity adjectives, the adjectives can float. When they float, they "smuggle" the degree operators associated with them to a position from which the operators can undergo degree operator movement.

\section{References}

Beck, Sigrid, Toshiko Oda \& Koji Sugisaki. 2004. Parametric variation in the semantics of comparison: Japanese vs. English. Journal of East Asian Linguistics 13. 289-344. https://doi.org/10.1007/s10831-004-1289-0.

Bhatt, Rajesh \& Shoichi Takahashi. 2011. Reduced and unreduced phrasal comparatives. Natural Language \& Linguistic Theory 29. 581-620. https://doi.org/10.1007/s11049-011-9137-1. 
Fitzpatrick, Justin. 2006. The syntactic and semantic roots of floating quantification. Cambrige, MA: MIT dissertation.

Fox, Danny \& Howard Lasnik. 2003. Successive-cyclic movement and island repair: The Difference between sluicing and VP-ellipsis. Linguistic Inquiry 34. 143-154. https://doi.org/10.1162/002438903763255959.

Kennedy, Christopher. 2002. Comparative deletion and optimality in syntax. Natural Language \& Linguistic Theory 20. 553-621. https://doi.org/10.1023/A:1015889823361.

Kennedy, Christopher \& Jason Merchant. 2000. Attributive comparative deletion. Natural Language \& Linguistic Theory 18. 89-146. https://doi.org/10.1023/A:1006362716348.

Lechner, Winfried \& Norbert Corver. 2017. Comparative deletion and comparative subdeletion. In Martin Everaert \& Henk C. van Riemsdijk (eds.), The Wiley Blackwell companion to syntax (2nd Edition). Hobken, NJ: John Wiley \& Sons.

Merchant, Jason. 2008. Variable island repair under ellipsis. In Kyle Johnson (ed.), Topics in Ellipsis, 132-153. Cambridge: Cambridge University Press.

Nakanishi, Kimiko. 2004. Domains of measurement: Formal properties of non-splitsplit quantifier constructions. Philadelphia: University of Pennsylvania dissertation.

Shimoyama, Junko. 2012. Reassessing crosslinguistic variation in clausal comparatives. Natural Language Semantics 20. 83-113. https://doi.org/10.1007/s11050-011-9076-8.

Sudo, Yasutada. 2015. Hidden nominal structures in Japanese clausal comparatives. Journal of East Asian Linguistics 24. 1-51. https://doi.org/10.1007/s10831-014-9125-7. 